\title{
Activity-dependent plasticity and gene expression modifications in the adult CNS
}

\author{
Daniela Carulli ${ }^{1,2}$ *, Simona Foscarin ${ }^{1,2}$ and Ferdinando Rossi ${ }^{1,2}$ \\ ${ }^{1}$ Department of Neuroscience, Neuroscience Institute of Turin, University of Turin, Turin, Italy \\ ${ }^{2}$ Neuroscience Institute Cavalieri-Ottolenghi, University of Turin, Turin, Italy
}

\author{
Edited by: \\ Simone Di Giovanni, University of \\ Tuebingen, Germany \\ Reviewed by: \\ Olivier Raineteau, Brain Research \\ Institute University of Zurich, \\ Switzerland \\ James W. Fawcett, Centre for Brain \\ Repair, UK

\section{*Correspondence:} \\ Daniela Carulli, Neuroscience \\ Institute Cavalieri-Ottolenghi, Regione \\ Gonzole 10, 10043 Orbassano, Turin, \\ Italy. \\ e-mail: daniela.carulli@unito.it
}

Information processing, memory formation, or functional recovery after nervous system damage depend on the ability of neurons to modify their functional properties or their connections. At the cellular/molecular level, structural modifications of neural circuits are finely regulated by intrinsic neuronal properties and growth-regulatory cues in the extracellular milieu. Recently, it has become clear that stimuli coming from the external world, which comprise sensory inflow, motor activity, cognitive elaboration, or social interaction, not only provide the involved neurons with instructive information needed to shape connection patterns to sustain adaptive function, but also exert a powerful influence on intrinsic and extrinsic growth-related mechanisms, so to create permissive conditions for neuritic remodeling. Here, we present an overview of recent findings concerning the effects of experience on molecular mechanisms underlying CNS structural plasticity, both in physiological conditions and after damage, with particular focus on activity-dependent modulation of growth-regulatory genes and epigenetic modifications.

Keywords: activity-dependent plasticity, neuritic remodeling, experience, enriched environment, growth-regulatory cues, epigenetics

\section{INTRODUCTION}

Adaptation of living organisms to changing environmental demands mostly depends on plasticity of the nervous system, namely the capability of neurons to modify their structure, connectivity, and functional properties. Structural modifications of neural circuits comprise a wide range of phenomena, including rewiring of existing connections and integration of new neurons in pre-existing networks. The current notion is that any process leading to structural remodeling of the nervous tissue is determined by the interplay between intrinsic neuronal properties and growth-regulatory cues expressed in the CNS microenvironment. Nonetheless, it is clear that plastic processes at the cellular/molecular level are conditioned by the concurrent interaction of the entire organism with the external world. Indeed, stimuli coming from the external environment (in a word "experience"), which comprise sensory inflow, motor activity, cognitive elaboration, and social interaction, exert a strong influence on the biological processes underlying the shaping of neural circuits (Sale et al., 2009). Neural circuits are particularly sensitive to experience during restricted phases of postnatal development, called critical periods, in which specific patterns of electrical activity, induced by specific experience events, contribute to refine neural connections to allow the emergence of adaptive function (Hensch, 2004). Over the last few years, however, it has become increasingly evident that experience also exerts a powerful influence on the function and structure of neuronal circuits in adult life, thereby strongly affecting biological mechanisms underlying information processing, memory formation and storage, and functional recovery after damage. Experience-dependent plasticity is initiated when neuronal activation triggers intracellular signaling pathways, from the synapse to the nucleus, that modulate gene expression. The products of such activity-dependent genes fine-tune neural circuits by strengthening or weakening synaptic connections or by altering synapse numbers, ultimately leading to profound changes of brain wiring and information processing.

In this review, we will discuss recent findings regarding cellular and molecular processes responsible to produce activity-induced structural remodeling of neural networks. Furthermore, we will focus on activity-dependent modifications of the expression of genes involved in neuritic growth.

\section{EXPERIENCE AND PHYSIOLOGICAL PLASTICITY}

It has been clear for almost two decades that cortical representations of sensory or motor peripheries are strongly affected by experience in adult animals. The cortex can expand areas to represent particular peripheral input sources according to the quality and quantity of their use. For example, in monkeys trained to discriminate with one of their digits between successive vibratory stimuli of different frequencies, the population of neurons responding to the skin stimulation site was enlarged several-fold (Recanzone et al., 1992a,b). In a related human study, PascualLeone and Torres (1993) analyzed differences in the hand representations of adults who had become proficient as Braille readers. Using magneto-encephalography, these authors showed that the scalp area over which potentials were recorded was significantly larger for the right index (reading) finger as compared with the left finger or as compared with the right finger of non-Braille readers. Representations of parts of the hand that were not employed in Braille reading were, in contrast, differentially smaller than in control hands. Similarly, it has been shown that the somatosensory 
representation of the digits of the left hand of string players is larger in comparison to that of the right hand fingers or to the left hand finger representation of control subjects (Elbert et al., 1995).

Other examples of how representational maps, such as those in primary cortical sensory areas ( $\mathrm{S} 1, \mathrm{~A} 1$, or $\mathrm{V} 1)$, can be remodeled by inducing changes in input sources come from denervation experiments. Transecting the median nerve of a monkey removes part of the digits input to $S 1$, but does not result in a permanent large area of unresponsive cortex. Indeed, immediately after transection, inputs from neighboring cortical areas are unmasked in a limited sector of the deafferented cortex. Over the course of a few weeks, representations of the bordering skin surfaces progressively expand to occupy increasingly larger portions of the former median nerve cortical representational zone (Merzenich et al., 1983a,b). Similarly, after the amputation of one digit, most of the cortex that originally responded only to the skin surfaces of the missing digit becomes responsive to inputs from adjacent digits or the subjacent palm (Merzenich et al., 1984). Other examples of reorganization in adult somatosensory cortex in response to denervation or amputation have been reported in the raccoon (Rasmusson, 1982; Kelahan and Doetsch, 1984), flying fox (Calford and Tweedale, 1988), cat (Kalaska and Pomeranz, 1979), and rat (Wall and Cusick, 1984). One of the most dramatic examples of cortical reorganization was reported by Pons et al. (1991). These authors mapped the cortex of monkeys that had undergone dorsal root avulsion (C2-T4) several years before, thereby depriving a cortical area of over $1 \mathrm{~cm}^{2}$ of its normal input from the arm and hand. All these deprived areas developed novel responses to neighboring skin areas, including the face and chin. A similar reorganization is seen in the adult human cortex. After amputation of an arm, sensory inputs from the face activate the hand area of the somatosensory cortex, therefore stimuli on the face can elicit sensations referred to the phantom limb (Ramachandran, 1993). Different mechanisms may underlie cortical map reorganization following peripheral input loss, ranging from unmasking of latent intracortical connections, to growth of intracortical axons or sprouting of subcortical fibers (see for review Navarro et al., 2007).

In the rodent barrel cortex, which processes tactile information from the facial vibrissae, experience-dependent plasticity has been reported following different types of sensory input manipulation. Trimming a subset of mystacial whiskers causes experiencedependent changes in receptive fields, such as potentiation of the responses to spared whiskers stimulation, which is detected after a day and progresses over several weeks (Fox, 2002). Following vibrissectomy that spared a row of whiskers, dextran injections into spared barrels label axons extending for significantly greater distances than after injections into deprived or control barrels. Also, the total axonal density in the spared barrels is 70\% higher than in the deprived or control barrels (Kossut and Juliano, 1999). Moreover, single whisker stimulation increases the total synaptic density in the corresponding cortical barrel (Knott et al., 2002).

Studies in the auditory and the visual cortex also highlighted the high capacity of the adult brain to adapt to input changes. After restricted monaural lesions of the cochlea there is a reorganization of the tonotopic map in response to information coming from the injured ear (Robertson and Irvine, 1989; Rajan et al.,
1993). One month after cochlear lesion, neurons in the deprived cortex responded to tone frequencies adjacent to the frequency range affected by the lesion. Bilateral lesions to the high-frequency cochlear sector in monkeys also produced an expanded representation of frequencies neighboring those whose inputs had been abolished (Schwaber et al., 1993). After focal lesions to the retina, collateral axons from neurons surrounding the scotoma in the visual cortex branch into the deprived area (Darian-Smith and Gilbert, 1994). In parallel, spine dynamics increase in the deafferented region of the visual cortex, suggesting that deprived neurons sample the neuropil searching for active presynaptic inputs (Keck et al., 2008).

In addition to structural changes reported in axonal projections and dendrites (reviewed in Fox and Wong, 2005; Hickmott and Steen, 2005; Broser et al., 2007), which typically occur in several days or weeks, very rapid remodeling (hours to days) of spines and synapses occurs in response to experience. For example, dendritic spines of pyramidal cells appear, disappear, and change shape on this time scale in vivo, and these dynamics are increased by sensory manipulations, including whisker or visual deprivation (Trachtenberg et al., 2002; Mataga et al., 2004; Oray et al., 2004; Holtmaat et al., 2006; Knott et al., 2006), or peripheral nerve injury (Kim and Nabekura, 2011). Spine formation and retraction can be associated with synapse formation and elimination (Trachtenberg et al., 2002; Holtmaat et al., 2006).

Activity-dependent changes in synaptic connections between neurons are believed to play a major role in learning and memory formation. While short-term memory might rely mainly on strengthening and weakening of pre-existing synapses, long-term storage of information is thought to require structural reorganization of neuronal networks, formation of new synapses, and loss of existing ones (Bailey and Kandel, 1993; Moser et al., 1994; Engert and Bonhoeffer, 1999; Moser, 1999; Martin et al., 2000; Kolb et al., 2008; Neves et al., 2008). In addition, motor learning in acrobatic conditions is associated with an increase in synapse number in the cerebellar (Black et al., 1990) and in the motor cortex (Kleim et al., 1996), whereas development of the conditioned eyeblink response is associated with neosynaptogenesis in the cerebellar nuclei (Kleim et al., 2002). Specific structural modifications may serve to store information about past experiences and thereby endow the cortex with an improved ability to adapt to similar conditions in the future. Indeed, structural changes at the level of dendritic spines in the visual cortex following monocular deprivation can outlast the original experience (Hofer et al., 2009). Similarly, training in a forelimb reaching task or on a rotating rod rapidly induces formation of new spines in the motor cortex, which are stabilized by subsequent training sessions and endure after the end of training (Xu et al., 2009; Yang et al., 2009).

\section{ENVIRONMENTAL ENRICHMENT}

Fundamental contributions to our understanding of the effects of external stimuli on brain plasticity came from the studies by Rosenzweig et al. (1978), who introduced environmental enrichment as a protocol to investigate the influence of the environment on brain and behavior. Enriched environment is "a combination of complex inanimate stimuli and social stimulation." It refers to housing conditions that facilitate sensory, motor, cognitive, and 
social stimulation (i.e., a large cage containing various objects, tubes, and running wheels, in which a numerous colony of individuals is housed). In the initial studies, the effects of environmental stimuli on parameters such as total brain weight (Bennett et al., 1969; Henderson, 1970, 1973; Ferchmin and Bennett, 1975), total DNA or RNA content (Mushynski et al., 1973; Uphouse and Bonner, 1975; Henderson, 1976), or total brain proteins were measured (Levitan et al., 1972; Jørgensen and Bock, 1979). Subsequently, many studies have shown that environmental stimulation elicits a variety of plastic modifications in the adult brain, ranging from synaptic remodeling and dendritic growth (Greenough et al., 1985; Beaulieu and Colonnier, 1987) to gliogenesis (Altman and Das, 1964; Diamond et al., 1966; Szeligo and Leblond, 1977), angiogenesis (Black et al., 1990; Isaacs et al., 1992; Kleim et al., 1996; Swain et al., 2003), and neurogenesis (Kempermann et al., 1997, 1998; Gould et al., 1999; Van Praag et al., 1999; Ambrogini et al., 2000). At the behavioral level, enrichment enhances learning and memory (Garcia-Segura et al., 1978), reduces memory decline in aged animals (Mohammed et al., 1993; Kempermann et al., 1998; Winocur, 1998; Soffie et al., 1999), decreases anxiety, and increases exploratory activity (Huck and Price, 1975; Francis et al., 2002; Morley-Fletcher et al., 2003). Enrichment-induced potentiation of learning and memory is generally attributed to the concomitant remodeling of neural circuits connections, although the direct link between cellular changes and functional modifications is not always established. On the other hand, some of the effects produced by enriched environment can be induced by exposition to specific components of the variety of external stimuli. For instance, increased physical activity alone (through spontaneous access to running wheels or forced running on treadmills) improves learning (Black et al., 1990; Kleim et al., 1996), promotes angiogenesis (Black et al., 1990; Isaacs et al., 1992; Swain et al., 2003), boosts hippocampal cell proliferation and survival (Kempermann et al., 1997, 1998; Gould et al., 1999; Van Praag et al., 2000), and stimulates the genesis of cortical microglia (Altman and Das, 1964; Diamond et al., 1966; Szeligo and Leblond, 1977). In general, different types of experience produce specific morpho-functional adaptation in the nervous tissue. Hence, while running boosts neurogenesis in the adult dentate gyrus, yoked swimming or maze training have no significant effects (Van Praag et al., 1999). Similarly, skill motor training stimulates synaptic reorganization in the motor cortex, strength training modifies intraspinal circuits, and endurance training promotes angiogenesis (Adkins et al., 2006).

\section{EXPERIENCE AND COMPENSATORY PLASTICITY FOLLOWING CNS INJURY}

Following CNS injury, compensatory processes can be initiated even without any particular pharmacological or rehabilitative intervention. Following different types of spinal cord injury (SCI), spontaneous sprouting from spared projections or propriospinal relays is paralleled by different degrees of functional recovery (Weidner et al., 2001; Bareyre et al., 2004; Ballermann and Fouad, 2006; Courtine et al., 2008). Conversely, after ablation of the hand representation area in the motor cortex of the squirrel monkey, a transient deficit in the use of the affected hand is paralleled by shrinkage of the cortical map (Nudo et al., 1996a). Recovery of motor function, however, is accompanied by enlargement of the hand representation in the premotor cortex and extensive reorganization and sprouting in the sensory cortex (Dancause et al., 2005). Moreover, 8 weeks after an infarct in the forelimb representation area, forelimb stimulation evoked a depolarization in the forelimb cortex that propagates into the adjacent areas with longer latency and duration (Brown et al., 2009). At the neuronal level, although a stroke determines loss of dendritic spines, the remaining ones become longer and undergo faster turnover (Brown et al., 2007, 2009).

Even if a certain degree of plasticity and recovery can be achieved spontaneously, the practice of the impaired function ameliorates the final outcome. Following ablation of the hand representation area in the motor cortex, task-specific rehabilitation induces the expansion of the hand representation in adjacent undamaged zones, associated with significant behavioral recovery (Nudo et al., 1996b). After removal of the forelimb representation area in the rat motor cortex, dendritic arborizations of layer $\mathrm{V}$ pyramidal neurons in the contralateral cortex show transient extension of new branches (Jones and Schallert, 1994). Interestingly, this plastic effect is modulated by the use of either the spared or the affected limb. Indeed, the expansion of dendritic arbors is mainly due to disuse of the affected limb and consequent intensified use of the spared one, and it can be counteracted by immobilization of the latter limb. On the contrary, dendritic expansion does not occur in the intact motor cortex, even if the contralateral limb is overused. Thus, plasticity in the spared motor cortex depends on both the presence of injury on the contralateral side and enhanced use of the unaffected limb (Jones and Schallert, 1994; Kozlowski et al., 1996).

One of the strategies to improve recovery after a CNS injury is therefore to exploit experience- and activity-based training. Enriched environment has been proven to reduce different functional defects after CNS injury. Exposure to enriched environment early after a contusive SCI improves rat scores on the Basso, Beattie, and Bresnahan (BBB) motor assessment and reduces allodynia but not hyperalgesia. These effects are paralleled by reduced formation of cystic cavities both in the white and in the gray matter (Berrocal et al., 2007). Enriched environment results effective in ameliorating BBB score even if it is initiated in the chronic phase, 3 months after a contusive SCI in the rat, and positive effects are already visible 2 weeks after the beginning of the treatment (Fischer and Peduzzi, 2007). Following SC hemisection, enriched environment also modulates spine dynamics in the motor cortex by counteracting the injury-induced spine enlargement and elongation (Kim et al., 2008). It is important to note that enriched environment stimulates spine remodeling in the whole brain in intact animals (Globus et al., 1973; see for review Nithianantharajah and Hannan, 2006), but exerts specific and stronger effects in the affected motor cortex, acting on spines that have been primed for remodeling by the SCI (Kim et al., 2008).

It has been demonstrated that the combination of enriched environment together with specific training is highly successful in promoting plasticity and functional recovery. Following middle cerebral artery occlusion, the association of enriched environment and skilled reaching task induces significant improvement in forelimb motor function in 4 weeks, and further behavioral improvement up to 9 weeks. The beneficial effects are paralleled 
by increase in dendritic length and complexity in the contralateral spared cortex (Biernaskie and Corbett, 2001). Similar results have been obtained after spinal cord hemisection at the C4 level: in this condition, the combined therapy with enriched environment and targeted training for forelimbs and hindlimbs induces an increase in the number of fibers that sprout in the corticospinal tract (CST; Dai et al., 2009). Thus, the combination of enriched environment early after injury with tasks that encourage the practice of affected functions improves long-term functional outcome regardless of initial lesion exacerbation due to the early onset of the therapy (Biernaskie et al., 2004).

Two main factors influence the course and outcome of activitybased therapies: (1) the moment when rehabilitation is initiated and the ensuing duration of the treatment; (2) the specificity of the training procedure.

(1) After a lesion of the forelimb representation in the rat cortex, immediate forced use of the affected limb exacerbates sensorimotor cortical lesion and hampers functional recovery. At the anatomical level, the expansion of the injury can be due to excitotoxic mechanisms and/or metabolic alterations in the surrounding tissue. At the behavioral level, the lack of functional recovery can be due to the impossibility to learn alternative strategies by the non-impaired limb during the early post-lesion period (Kozlowski et al., 1996). On the other hand, unilateral lesion of the rat CST followed by immediate immobilization of the non-impaired forelimb leads to full motor recovery in 3 weeks, together with enhanced sprouting of CST fibers from the intact side and upregulation of inflammation-related factors, ion channels and transporters, growth factors, guidance cues, extracellular matrix components, and molecules involved in synapse formation (Maier et al., 2008). This sharp difference in the outcome after the application of the same treatment is probably due to the different lesion conditions. Indeed, a CST transection only interrupts descending tracts at the cord level, leaving cell bodies undamaged and less prone to excitotoxic insults. Thus, the same therapeutic treatment can lead to good or bad effects depending on the particular injury conditions. Moreover, it has been demonstrated that combined therapy of enriched environment with balance and coordination trainings induces functional recovery both if begun immediately or 1 week after an infarct, but the loss of cortical tissue is reduced if training is delayed (Risedal et al., 1999).

(2) Not all the types of experimental training have the same effect on plasticity and functional recovery. In the somatosensory system of the rat, a spinal cord contusion leads to allodynia that responds differently to specific training procedures. Indeed, allodynia fully recovers in 35 days if the training is on a treadmill, it partially and transiently ameliorates if training is swimming, and it remains unaltered if training is limited to upright standing (Hutchinson et al., 2004). Treadmill training is also effective in ameliorating motor defects that follow a SC hemisection (Goldshmit et al., 2008). Trained mice improve in the BBB over their controls, far better in walking and climbing on a grid, and recover walking kinematic and footprints in 5 weeks. Treadmill trained mice also show more axonal sprouting, increased synapse formation, and less muscle atrophy. On the other hand, treadmill training does not ameliorate grip strength, which also depends on sensory input (Goldshmit et al., 2008). Training specificity is very important to recover highly skilled tasks. After a transection of the CST, forelimb functionality is reduced in general, but acquired skills are most severely impaired (Whishaw et al., 1998; Starkey et al., 2005; Anderson et al., 2007). Interestingly, recovery of forelimb function after SCI occurs only when pharmacological intervention that enhances sprouting is combined with taskspecific rehabilitation. On the contrary, a non-specific general rehabilitation protocol (enriched environment) results in worse performance on specific forelimb tasks than no rehabilitation at all. Nonetheless, it results in better performance on more general behaviors (i.e., ladder walking; García-Alías et al., 2009). Moreover, task-specific training has been shown to enable injured animals to ameliorate their skilled behaviors, but to worsen their performance in related but untrained tasks (Girgis et al., 2007; Dai et al., 2009; Kuerzi et al., 2010). On the whole, general rehabilitation in which the level of physical activity is increased can produce behavioral improvements in many conditions. However, task-specific training is generally more effective in improving the recovery of the functions that are practiced, although to the detriment of behaviors that are not practiced.

Not only post-operative trainings are beneficial in reducing lesioninduced deficits, but also exercise before lesions can be highly advantageous. It has been recently demonstrated that exposure of adult rats to enriched environment before hemi-cerebellectomy accelerates recovery (Cutuli et al., 2011). Behavioral improvement and recovery of normal patterns of electrical activity in the striatum occur even if the animals are kept in standard cages. However exposure to enriched environment after injury boosts recovery and the effect is even stronger if the treatment is initiated before injury. At the morphological level, dendritic arborizations of striatal neurons are reduced in lesioned animals kept in standard cages, but return to basal levels if rats experience enriched environment after the injury, and are oversized if enriched environment starts before the lesion. Thus, exposure to enriched environment and active life exerts both a neuroprotective and growth promoting effect that potentiates the compensatory phenomena set up in response to injury. The formation of new synapses induced by enriched environment in intact animals may guarantee a reserve of connections that can be readily exploited to improve recovery after injury (Cutuli et al., 2011). On the whole, experience may precondition tissues to challenging metabolic functions, by increasing angiogenesis and neurogenesis, reducing the susceptibility to apoptosis and inhibitory molecules or increasing the expression of neurotrophic factors (see for review Kleim et al., 2003).

\section{ACTIVITY-DEPENDENT MODULATION OF GROWTH-REGULATORY CUES}

In order to trigger physiological or compensatory plasticity, external stimuli must modulate specific growth-regulatory signaling cascades and molecular cues. However, the precise mechanisms by which external stimuli influence growth control mechanisms are 
not fully elucidated. Neuronal activity appears to play a relevant role in this respect, controlling changes in gene expression patterns that lead to adaptive modifications of function and/or behavior. At glutamatergic synapses, activity leads to $\mathrm{Ca}^{++}$influx into the postsynaptic cell through activation of NMDA receptors, as well as voltage sensitive $\mathrm{Ca}^{++}$channels. $\mathrm{Ca}^{++}$entry into the cell activates different signaling pathways that converge on the nucleus to activate gene expression (see for review Lyons and West, 2011). Targets of these signaling cascades include the transcription factor CRE-binding protein (CREB), which plays a crucial role in long-term memory formation (Dash et al., 1990; Bourtchuladze et al., 1994) and other forms of plasticity (Mower et al., 2002). The expression of several immediate early genes, such as $c$-fos, $c$-jun, and $z i f / 268$, is also elicited in response to neuronal depolarization (Sheng and Greenberg, 1990), and parallels the build up of synaptic plasticity, such as LTP. Many other activity-regulated genes have been characterized which affect plasticity through various modifications of the synapse, including $\operatorname{rgs} 2, \operatorname{arclarg3.1,} \operatorname{cpg} 2$, homerla, snk, cpg15, arcadlin, npas4, narp (for a detailed characterization of the cellular functions of these genes, see Leslie and Nedivi, 2011). Furthermore, npas4 and narp modulate inhibitory circuit function (Lin et al., 2008; Chang et al., 2010), which is a crucial limiting factor for the induction of experience-dependent plasticity in the adult cortex (Harauzov et al., 2010; Chen et al., 2011). Interestingly, activation of hippocampal circuits by pharmacological or electrical stimulation also induces local changes in the expression of neuronal growth molecules (e.g., GAP-43, Bendotti et al., 1994; Holtmaat et al., 2003) and extrinsic regulatory cues (e.g., chondroitin sulfate proteoglycans - CSPGs, Heck et al., 2004; Schwarzacher et al., 2006), which have been associated with concomitant neuritic sprouting. Signaling molecules, such as NF$\kappa \mathrm{B}$, can be also elicited by electrical activity or synaptic stimulation (Wellmann et al., 2001; Meffert et al., 2003).

The expression of a large number of genes is also affected when animals are exposed to enriched environment. Many of those genes are involved in regulating neuronal structure, synaptic signaling, and structural remodeling that occur during neuronal growth or memory formation (Rampon et al., 2000; Vallès et al., 2011). For example, 3 or $6 \mathrm{~h}$ of exposure to enriched environment are sufficient to trigger the expression of genes encoding integrin alpha- 4 and GTPase RhoA, which are important for neuritogenesis and neuronal plasticity (Kogan et al., 1997; Mansuy et al., 1998), and of a cluster of genes encoding proteins involved in synaptic vesicle trafficking and neurotransmitter release, including synaptobrevin and clathrin-AP2 (Rampon et al., 2000).

One of the most extensively characterized activity-regulated genes is $b d n f$ (Maffei, 2002). BDNF belongs to the neurotrophin family (NGF, BDNF, NT3, and NT4/5), which are secreted proteins that have emerged as important regulators of neuronal survival, differentiation, neuritic growth, and plasticity (Reichardt, 2006). The resulting effects of BDNF on cellular and molecular plasticity (and ultimately behavior) are due to activation of other activity-dependent genes, such as arc/arg3.1, narp, cgp15 (Wibrand et al., 2006), or of different intracellular signaling cascades that, in turn, regulate the transcription of neuronal growth genes, such as GAP-43 and synapsin 1 (Vaynman and Gomez-Pinilla, 2005; Wibrand et al., 2006; Cotman et al., 2007). Expression of BDNF can be induced by specific external stimuli or physical activity (Gòmez-Pinilla et al., 2002; Vaynman and Gomez-Pinilla, 2005). For example, enriched environment, which reinstates ocular dominance plasticity in the adult, leads to increased BDNF expression in the visual cortex (Sale et al., 2007; Baroncelli et al., 2010). In the rat barrel cortex, naturalistic whisker use (obtained by exposing animals to external conditions that mimic natural environment) stimulates the expression of BDNF as well as CREB, synapsin 1, and GAP-43, whereas sensory deprivation has opposite effects (Gòmez-Pinilla et al., 2011). Concerning reparative phenomena, voluntary exercise boosts the expression of BDNF, synapsin 1, and GAP-43 in sensory ganglia and, in parallel, promotes peripheral nerve regeneration in vivo and axonal outgrowth from cultured DRG neurons (Molteni et al., 2004). Following SCI, the amelioration of allodynia induced by treadmill training and the reduced occurrence of cystic cavities observed after enriched environment are accompanied by the return of BDNF expression to normal levels (Hutchinson et al., 2004; Berrocal et al., 2007). Evidence favoring a BDNF-mediated effect on structural plasticity and motor recovery after SCI has been obtained by interfering with the function of the neurotrophin: in both sedentary and exercised rats with SCI, pretreatment with a BDNF inhibitor reduces the expression of CREB and synapsin 1, hampers spinal learning, and enhances motor asymmetry during treadmill locomotion (Ying et al., 2008).

Recently, it has become clear that specific physiological stimuli can also impact the expression of growth-inhibitors of the extracellular milieu (Rossi et al., 2007), such as CNS myelin molecules (Nogo-A, MAG, and OMgp, see for review Xie and Zheng, 2008) and extracellular matrix components (e.g., CSPGs, tenascin-R, see for review Kwok et al., 2008). Voluntary running leads to decreased expression of myelin components both in the intact spinal cord (Ghiani et al., 2007), and in the injured cortex (Chytrova et al., 2008), and all these effects depend on BDNF activity (Ghiani et al., 2007; Chytrova et al., 2008). Experience-dependent changes of extracellular matrix components have been investigated in the hypothalamo-neurohypophysial system, where magnocellular neurons of the hypothalamic supraoptic nucleus undergo dramatic structural plasticity and synaptogenesis in response to chronic salt overload. In this condition, specific CSPGs in pericellular nets are down-regulated, in concomitance with retraction of glial processes and ensuing reorganization of neuronal connectivity (Miyata et al., 2004; Morita et al., 2010).

The organization of CSPGs into perineuronal nets, which are specialized structures surrounding some neuronal types (Brauer et al., 1984; Hockfield et al., 1990; Pizzorusso et al., 2002; Carulli et al., 2006), is a key event in the control of CNS plasticity by the extracellular matrix (Gogolla et al., 2009; Carulli et al., 2010). Interestingly, reduced density of perineuronal nets is reported in the visual cortex after enriched environment, in parallel with recovery of visual acuity and ocular dominance of adult amblyopic rats (Sale et al., 2007). Although changes of perineuronal nets parallel functional adaptation, in this experimental model they cannot be directly related to structural remodeling of the underlying circuits. However, exposure to enriched environment induces significant neuritic remodeling in the deep cerebellar nuclei, which is accompanied by conspicuous reduction of perineuronal nets enwrapping 
the same nuclear neurons. These extracellular matrix changes are due to reduced synthesis of several perineuronal net components, including hyaluronan synthase, link protein 1 and aggrecan, and simultaneous activation of matrix degrading enzymes, namely matrix metalloproteinase (MMP)-2 and -9 (Foscarin et al., 2011). These data suggest that external stimuli may shift the balance between synthesis and removal of matrix components in order to facilitate neuritic growth by locally dampening the activity of environmental inhibitory cues. In this context, growing evidence highlights the role of proteases in the removal of inhibitory extracellular matrix during activity-dependent plasticity. In particular, MMP-9 and, to a lesser extent, MMP-2 are upregulated in the hippocampus following epileptic seizures and influence seizureinduced plastic changes (Szklarczyk et al., 2002; Jourquin et al., 2003). MMP-9, which is maximally expressed along dendrites and glutamatergic synapses (Konopacki et al., 2007; Gawlak et al., 2008; Wilczynski et al., 2008), degrades the extracellular matrix protein $\beta$-dystroglycan, enhances the motility of NMDA receptors and is involved in the elimination of dendritic spines and aberrant synaptic contacts (Michaluk et al., 2007, 2009; Wilczynski et al., 2008).

An important function in activity-dependent plasticity has also been demonstrated for tissue plasminogen activator (tPA), which cleaves extracellular plasminogen and converts it to enzymatically active plasmin. tPA has been implicated in synaptic remodeling associated with LTP (Baranes et al., 1998) and facilitates seizure-induced mossy fiber sprouting (Wu et al., 2000). BDNF, NT3, and NT4 stimulate tPA transcription, activation, and secretion (Fiumelli et al., 1999). After glutamate application, neuronal depolarization or environmental enrichment, tPA protein level, and activity increase (Gualandris et al., 1996; Shin et al., 2004; Horii-Hayashi et al., 2011). Moreover, tPA is essential for experience-dependent plasticity in the visual cortex during the critical period (Mataga et al., 2002, 2004; Oray et al., 2004).

Another protease that is regulated during neuronal activity is neurotrypsin. Neuronal depolarization induces its recruitment to presynaptic terminals, where it is released and influences synaptic remodeling through proteolytic activity (Frischknecht et al., 2008).

\section{EXPERIENCE-DEPENDENT EPIGENETIC MODIFICATIONS}

In the last years it has become clear that environmental signals modulate gene expression not only through activation of specific transcription factors but also through epigenetic mechanisms (Fagiolini et al., 2009; Sweatt, 2009). Epigenetics is the ensemble of alterations in gene functions that are heritable but that cannot be explained by changes in the DNA sequence itself (see for review Jaenisch and Bird, 2003; Bird, 2007). At the molecular level, epigenetics includes biochemical modifications of the DNA and histone proteins, the major constituents of chromatin. Epigenetic mechanisms that are part of the gene-environment interface include: (1) DNA methylation; (2) histone post-translational modification.

(1) DNA methylation is a direct chemical modification that adds a $\mathrm{CH}_{3}$ group to a cytosine side-chain. Methylation of cytosines recruits methyl-DNA binding proteins, which have a transcription-regulatory domain. This domain anchors adapter/scaffolding proteins, which in turn recruit histone deacetylases (HDACs) to the site. The latter enzymes remove acetyl groups from histone core proteins, leading to local compaction of chromatin and transcriptional suppression (Figure 1; Sweatt, 2009, but see also Chahrour et al., 2008 about transcriptional activation following DNA methylation).

(2) Post-translational modifications of histones are crucial to modulate the overall structure of chromatin. In particular, the N-terminal tails of histones are highly accessible to enzymatic transformation and are sites for multiple modifications, including acetylation, phosphorylation, methylation, ubiquitination, and sumoylation (Peterson and Laniel, 2004; Berger, 2007). Histone modifications, such as histone acetylation and phosphorylation, facilitate the unraveling of DNA around the histone core resulting in the recruitment of the transcriptional machinery needed to mediate cell- and promoter-specific gene expression. Other modifications, such as methylation, have different positive or negative effects on gene transcription, depending on the modified amino acid residue and the number of added methyl groups (Berger, 2007). The most extensively studied histone modification in the CNS is acetylation. It is catalyzed by histone acetyltransferases, while the reversal reaction is regulated by HDACs. HDAC inhibitors, such as trichostatin A and sodium butyrate, represent the principal mean to manipulate the epigenome pharmacologically. Two main signaling cascades have been implicated in

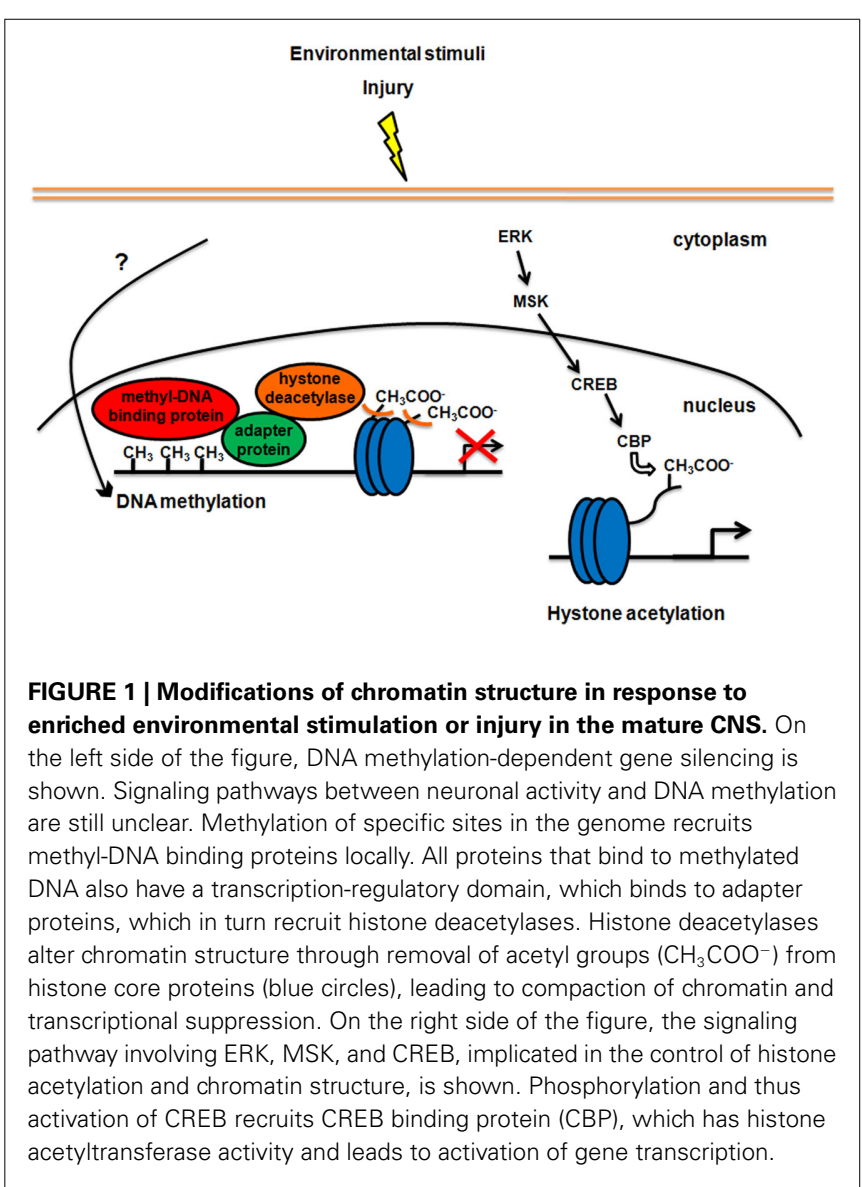


the control of histone acetylation and chromatin structure in the mature CNS. One pathway involves the mitogenactivated protein kinase (MAPK) superfamily, exemplified by the ERK/MSK/CREB pathway. Phosphorylation and thus activation of CREB recruits CREB binding protein (CBP), which has histone acetyltransferase activity, regulating local chromatin structure as part of CREB-dependent activation of gene transcription (Sweatt, 2009; Figure 1). The second known category of signaling pathway regulating chromatin structure is the NF- $\kappa \mathrm{B}$ cascade. NF- $\kappa \mathrm{B}$ is a DNA binding transcription factor that controls histone acetylation (Sweatt, 2009).

Histone modifications have been implicated in the regulation of ocular dominance plasticity (Putignano et al., 2007). In juvenile mice, visual stimulation that activates CREB-mediated gene transcription also induces ERK-dependent histone $\mathrm{H} 3$ phosphorylation and $\mathrm{H} 3-\mathrm{H} 4$ acetylation. In adult animals, visual stimulation induces weak CREB-mediated gene expression and $\mathrm{H} 3-\mathrm{H} 4$ posttranslational modification, suggesting that a decrease in the ability of visual experience to drive changes in histone phosphorylation and acetylation could be involved in the closure of the critical period. Indeed, stimulation of histone acetylation by means of the HDAC inhibitor trichostatin re-opens the critical period, restoring the capacity for ocular dominance plasticity in the adult visual cortex (Putignano et al., 2007).

Epigenetic tagging of the genome has also a crucial role in adult brain plasticity, such as during consolidation of long-term memory. Acetylation of histone $\mathrm{H} 3$ is significantly increased in the hippocampus after training in a contextual fear conditioning paradigm, and inhibition of cellular processes required for formation of long-term fear memory blocks the memory-associated increase in H3 acetylation (Levenson et al., 2004). Block of the activity of histone acetyltransferases also impairs long-term memory formation (Korzus et al., 2004; Oliveira et al., 2007). Conversely, direct infusion of the HDAC inhibitor trichostatin A into the amygdala significantly enhances the establishment of fear memory (Yeh et al., 2004). Similarly, systemic administration of the HDAC inhibitor sodium butyrate prior to contextual fear conditioning enhances formation of fear memory (Levenson et al., 2004). Vecsey et al. (2007) demonstrated that these memory-enhanced effects of HDAC inhibitors depend on the CREB pathway, nicely unifying the HDAC inhibitor studies with the CBP-histone acetyltransferase oriented studies.

Interestingly, histone acetylation is linked to histone methylation during consolidation of fear-conditioned memories in the hippocampus. Here, transcriptionally silent regions contain methylation of histone $\mathrm{H} 3$ at lysine 9, whereas active genes correlate with methylation of histone $\mathrm{H} 3$ at lysine 4 . Treatment of animals with the HDAC inhibitor sodium butyrate elevates methylation of histone $\mathrm{H} 3$ at lysine 4 and decreased methylation of histone $\mathrm{H} 3$ at lysine 9. Moreover, inhibitors of DNA methyltransferases in the adult CNS block hippocampal long-term potentiation in vitro (Levenson et al., 2006), and impairs memory formation after contextual fear conditioning (Miller et al., 2008). Heterozygous deletion of a known regulator of histone methylation also leads to significant deficits in memory consolidation (Gupta et al., 2010).
Regulation of chromatin structure is also involved in extinction of memories, a learning process through which the ability of a previously conditioned stimulus to evoke a conditioned response is diminished (Bredy et al., 2007). For instance, extinction of conditioned fear is accelerated when animals are administered HDAC inhibitors (Lattal et al., 2007; Bredy and Barad, 2008).

The role of enhanced experience in triggering adult brain plasticity through histone modifications has been elegantly demonstrated by Fischer et al. (2007). They showed that enriched environment induces hippocampal and cortical acetylation and methylation of histones 3 and 4, in parallel with improving spatial memory capacity, and this improvement is mimicked by HDAC inhibitors. Both HDAC inhibitors and enriched environment facilitate associative learning in control mice, and also reinstate learning ability and recovery of memories in a mouse model of neurodegenerative disorders (Fischer et al., 2007). In this context, it has been also shown that enriched environment or exercise specifically lead to sustained epigenetic modification of $b d n f$ gene promoters in the hippocampus, therefore influencing BDNF transcription (Gòmez-Pinilla et al., 2011; Kuzumaki et al., 2011).

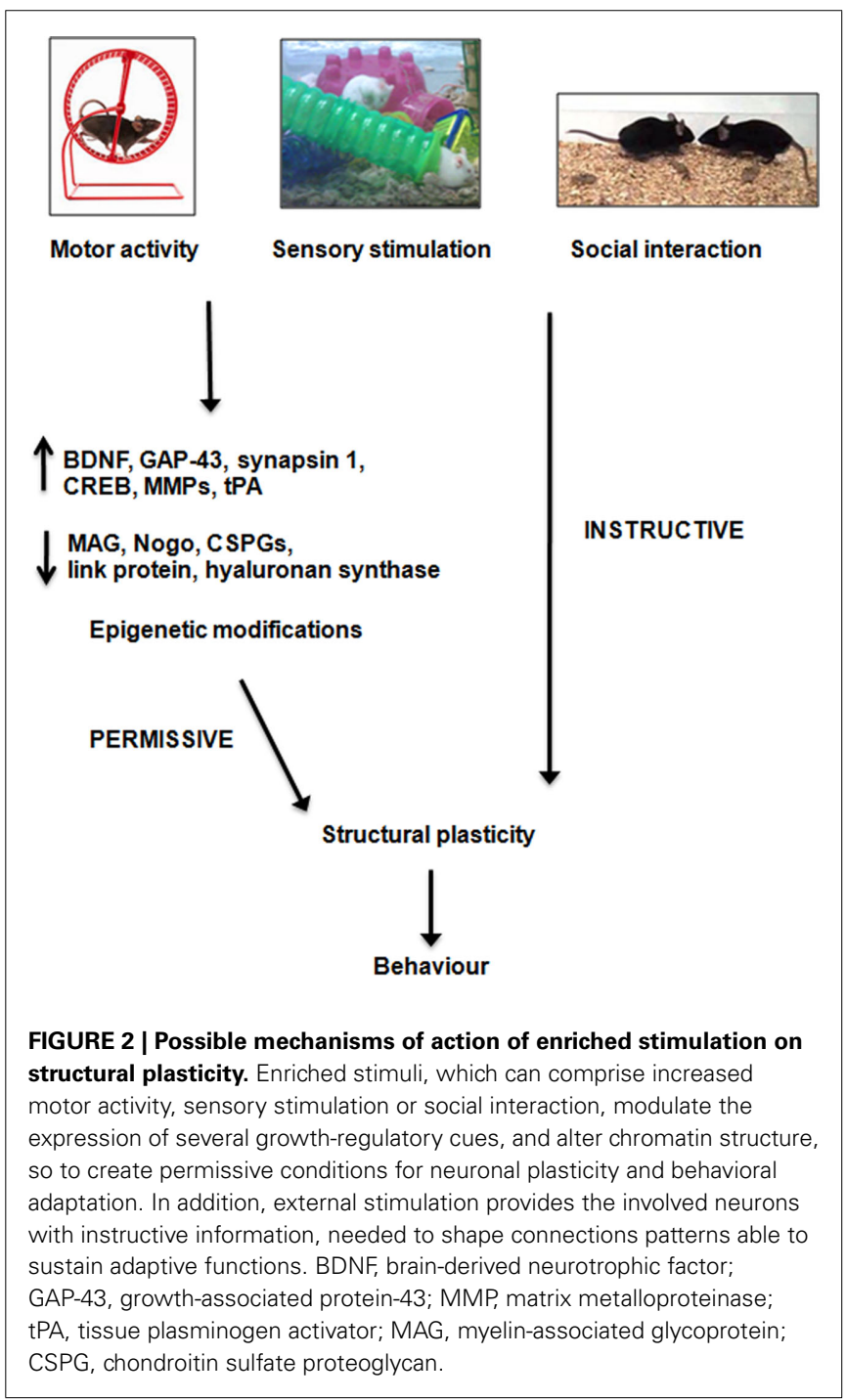


Overall, although there is increasing evidence highlighting an important role of epigenetics in the modulation of growth-gene expression and neurite outgrowth (see also Gaub et al., 2010,2011), further investigation is needed to disclose the precise mechanisms of epigenetic control on neural plasticity. This may allow us to manipulate epigenetic modifications in a specific and controlled manner in order to enhance plasticity and recovery following different forms of nervous system damage.

\section{CONCLUSION}

In the last few years, considerable progresses have been achieved in the knowledge of the mechanisms that link experience with cellular and molecular changes underlying neural adaptation to environmental demands. The emerging picture indicates that interaction with the external world exerts a dual, synergistic influence on plastic processes. On one side, external stimuli modulate the expression of both intrinsic neuronal growth properties and extrinsic regulatory molecules so to create permissive conditions

\section{REFERENCES}

Adkins, D. L., Boychuk, J., Remple, M. S., and Kleim, J. A. (2006). Motor training induces experience-specific patterns of plasticity across motor cortex and spinal cord. J. Appl. Physiol. 101, 1776-1782.

Altman, J., and Das, G. D. (1964). Autoradiographic examination of the effects of enriched environment on the rate of glial multiplication in the adult rat brain. Nature 204, 1161-1163.

Ambrogini, P., Cuppini, R., Cuppini, C., Ciaroni, S., Cecchini, T., Ferri, P., Sartini, S., and Del Grande, P. (2000). Spatial learning affects immature granule cell survival in adult rat dentate gyrus. Neurosci. Lett. 286, 21-24.

Anderson, K. D., Gunawan, A., and Steward, O. (2007). Spinal pathways involved in the control of forelimb motor function in rats. Exp. Neurol. 206, 318-331.

Bailey, C. H., and Kandel, E. R. (1993). Structural changes accompanying memory storage. Annu. Rev. Physiol. 55, 397-426.

Ballermann, M., and Fouad, K. (2006). Spontaneous locomotor recovery in spinal cord injured rats is accompanied by anatomical plasticity of reticulospinal fibers. Eur. J. Neurosci. 23, 1988-1996.

Baranes, D., Lederfein, D., Huang, Y. Y., Chen, M., Bailey, C. H., and Kandel, E. R. (1998). Tissue plasminogen activator contributes to the late phase of LTP and to synaptic growth in the hippocampal mossy fiber pathway. Neuron 21, 813-825.

Bareyre, F. M., Kerschensteiner, M., Raineteau, O., Mettenleiter, T. C.,
Weinmann, O., and Schwab, M. E. (2004). The injured spinal cord spontaneously forms a new intraspinal circuit in adult rats. Nat. Neurosci. 7, 269-277.

Baroncelli, L., Sale, A., Viegi, A., Maya Vetencourt, J. F., De Pasquale, R., Baldini, S., and Maffei, L. (2010). Experience-dependent reactivation of ocular dominance plasticity in the adult visual cortex. Exp. Neurol. 226, 100-109.

Beaulieu, C., and Colonnier, M. (1987). Effect of the richness of the environment on the cat visual cortex. J. Comp. Neurol. 266, 478-494.

Bendotti, C., Pende, M., and Samanin, R. (1994). Expression of GAP43 in the granule cells of rat hippocampus after seizure-induced sprouting of mossy fibers: in situ hybridization and immunocytochemical studies. Eur. J. Neurosci. 6, 509-515.

Bennett, E. L., Rosenzwig, M. R., and Diamond, M. C. (1969). Rat brain: effects of environmental enrichment on wet and dry weights. Science 163, 825-826.

Berger, S. L. (2007). The complex language of chromatin regulation during transcription. Nature 447, 407-412.

Berrocal, Y., Pearse, D. D., Singh, A., Andrade, C. M., McBroom, J. S., Puentes, R., and Eaton, M. J. (2007). Social and environmental enrichment improves sensory and motor recovery after severe contusive spinal cord injury in the rat. J. Neurotrauma 24, 1761-1772.

Biernaskie, J., Chernenko, G., and Corbett, D. (2004). Efficacy of rehabilitative experience declines with time

for structural remodeling of neural circuits. On the other side, the same stimuli provide the involved neurons with instructive information, needed to shape connection patterns able to sustain adaptive function (Figure 2). Such a powerful mechanism appears to play a relevant role in both physiological plasticity and injury-induced compensatory processes (Rossi et al., 2007). As a consequence, understanding all different aspects of plasticity from epigenetic modifications to molecular changes and circuit rewiring has strong translational implications. In addition to unraveling the mechanistic unfolding of neural plasticity, the numerous studies carried out in this field are producing a host of molecules and procedures that allow us to interfere and manipulate these processes with increasing efficacy and specificity. It is expected that, in the next future, strategies that combine specific stimulation paradigms (ranging from physical rehabilitation to psychotherapy) with targeted molecular/pharmacological manipulations will become more and more important for the treatment of a wide range of neural disorders or dysfunctions.

after focal ischemic brain injury. $J$. Neurosci. 24, 1245-1254.

Biernaskie, J., and Corbett, D. (2001). Enriched rehabilitative training promotes improved forelimb motor function and enhanced dendritic growth after focal ischemic injury. $J$. Neurosci. 21, 5272-5280.

Bird, A. (2007). Perceptions of epigenetics. Nature 447, 396-398.

Black, J. E., Isaacs, K. R., Anderson, B. J., Alcantara, A. A., and Greenough, W. T. (1990). Learning causes synaptogenesis, whereas motor activity causes angiogenesis, in cerebellar cortex of adult rats. Proc. Natl. Acad. Sci. U.S.A. 87, 5568-5572.

Bourtchuladze, R., Frenquelli, B., Blendy, J., Cioffi, D., Schutz, G., and Silva, A. J. (1994). Deficient long-term memory in mice with a targeted modulation of the cAMPresponsive element-binding protein. Cell 79, 59-68.

Brauer, K., Brückner, G., Leibnitz, L., and Werner, L. (1984). Structural and cytochemical features of perineuronal glial nets in the rat brain. Acta Histochem. 74, 53-60.

Bredy, T. W., and Barad, M. (2008). The histone deacetylase inhibitor valproic acid enhances acquisition, extinction, and reconsolidation of conditioned fear. Learn. Mem. 15, 39-45.

Bredy, T. W., Wu, H., Crego, C., Zellhoefer, J., Sun, Y. E., and Barad, M. (2007). Histone modifications around individual BDNF gene promoters in prefrontal cortex are associated with extinction of conditioned fear. Learn. Mem. 14 268-276.

Broser, P., Grinevich, V., Osten, P., Sakmann, B., and Wallace, D. J. (2007).
Critical period plasticity of axonal arbors of layer $2 / 3$ pyramidal neurons in rat somatosensory cortex: layer-specific reduction of projections into deprived cortical columns. Cereb. Cortex 18, 1588-1603.

Brown, C. E., Aminoltejari, K., Erb, H., Winship, I. R., and Murphy, T. H. (2009). In vivo voltage-sensitive dye imaging in adult mice reveals that somatosensory maps lost to stroke are replaced over weeks by new structural and functional circuits with prolonged modes of activation within both the peri-infarct zone and distant sites. J. Neurosci. 29, 1719-1734.

Brown, C. E., Li, P., Boyd, J. D., Delaney, K. R., and Murphy, T. H. (2007). Extensive turnover of dendritic spines and vascular remodeling in cortical tissues recovering from stoke. J. Neurosci. 27, 4101-4109.

Calford, M. B., and Tweedale, R. (1988). Immediate and chronic changes in responses of somatosensory cortex in adult flying-fox after digit amputation. Nature 332, 446-448.

Carulli, D., Pizzorusso, T., Kwok, J. C. Putignano, E., Poli, A., Forostyak, S., Andrews, M. R., Deepa, S. S., Glant, T. T., and Fawcett, J. W. (2010). Animals lacking link protein have attenuated perineuronal nets and persistent plasticity. Brain 133, 2331-2347.

Carulli, D., Rhodes, K. E., Brown, D. J., Bonnert, T. P., Pollack, S. J., Oliver, K., Strata, P., and Fawcett, J. W. (2006). Composition of perineuronal nets in the adult rat cerebellum and the cellular origin of their components. J. Comp. Neurol. 494, 559-577. 
Chahrour, M., Jung, S. Y., Shaw, C., Zhou, X., Wong, S. T., Qin, J., and Zoghbi, H. Y. (2008). MeCP2, a key contributor to neurological disease, activates and represses transcription. Science 320, 1224-1229.

Chang, M. C., Park, J. M., Pelkey, K. A., Grabenstatter, H. L., Xu, D., Linden, D. J., Sututla, T. P., McBain, C. J., and Worley, P. F. (2010). Narp regulates homeostatic scaling of excitatory synapses on parvalbuminexpressing interneurons. Nat. $\mathrm{Neu}$ rosci. 13, 1090-1097.

Chen, J. L., Li, C. M., Cha, J. W., So, P. T., Kubota, Y., and Nedivi, E. (2011). Structural basis for the role of inhibition in facilitating adult brain plasticity. Nat. Neurosci. 14, 587-594.

Chytrova, G., Ying, Z., and GòmezPinilla, F. (2008). Exercise normalizes levels of MAG and NogoA growth inhibitors after brain trauma. Eur. J. Neurosci. 27, 1-11.

Cotman, C. W., Berchtold, N. C., and Christie, L. A. (2007). Exercise builds brain health: key roles of growth factors cascades and inflammation. Trends Neurosci. 30, 464-472.

Courtine, G., Song, B., Roy, R. R., Zhong, H., Herrmann, J. E., Ao, Y., Qi, J., Edgerton, V. R., and Sofroniew, M. V. (2008). Recovery of supraspinal control of stepping via indirect propriospinal relay connections after spinal cord injury. Nat. Med. 14, 69-74.

Cutuli, D., Rossi, S., Burello, L., Laricchiuta, D., De Chiara, V., Foti, F., De Bartolo, P., Musella, A., Gelfo, F., Centonze, D., and Petrosini, L. (2011). Before or after does it matter? Different protocols of environmental enrichment differently influence motor, synaptic and structural deficits of cerebellar origin. Neurobiol. Dis. 42, 9-20.

Dai, H., MacArthur, L., McAtee, M., Hockenbury, N., Tidwell, J. L., McHugh, B., Mansfield, K., Finn, T., Hamers, F. P., and Bregman, B. S. (2009). Activity-based therapies to promote forelimb use after a cervical spinal cord injury. J. Neurotrauma 26, 19-32.

Dancause, N., Barbay, S., Frost, S. B., Plautx, E. J., Chen, D., Zoubina, E. V., Stowe, A. M., and Nudo, R. J. (2005). Extensive cortical rewiring after brain injury. J. Neurosci. 25, 10167-10179.

Darian-Smith, C., and Gilbert, C. D. (1994). Axonal sprouting accompanies functional reorganization in adult cat striate cortex. Nature 368, 737-740.

Dash, P. K., Hochner, B., and Kandel, E. R. (1990). Injection of the
cAMP-responsive element into the nucleus of Aplysia sensory neurons blocks long-term facilitation. Nature 345, 718-721.

Diamond, M. C., Law, F., Rhodes, H., Lindner, B., Rosenzweig, M. R., Kreck, D., and Bennett, E. L. (1966). Increases in cortical depth and glia numbers in rats subjected to enriched environment. J. Comp. Neurol. 128, 117-126.

Elbert, T., Pantev, C., Wienbruch, C., Rockstroh, B., and Taub, E. (1995). Increased cortical representation of the fingers of the left hand in string players. Science 270, 305-307.

Engert, F., and Bonhoeffer, T. (1999). Dendritic spine changes associated with hippocampal long-term synaptic plasticity. Nature 399, 66-70.

Fagiolini, M., Jensen, C. L., and Champagne, F. A. (2009). Epigenetic influences on brain development and plasticity. Curr. Opin. Neurobiol. 1, 207-212.

Ferchmin, P. A., and Bennett, E. L. (1975). Direct contact with enriched environment is required to alter cerebral weights in rat. J. Comp. Physiol. Psychol. 88, 360-367.

Fischer, A., Sananbenesi, F., Wang, X. Dobbin, M., and Tsai, L. H. (2007). Recovery of learning and memory is associated with chromatin remodelling. Nature 447, 178-182.

Fischer, F. R., and Peduzzi, J. D. (2007). Functional recovery in rats with chronic spinal cord injuries after exposure to an enriched environment. J. Spinal Cord Med. 30, 147-155.

Fiumelli, H., Jabaudon, D., Magistretti, P. J., and Martin, J. L. (1999). BDNF stimulates expression, activity and release of tissue-type plasminogen activator in mouse cortical neurons. Eur. J. Neurosci. 11, 1639-1646.

Foscarin, S., Ponchione, D., Pajaj, E., Leto, K., Gawlak, M., Wilczynski, G. M., Rossi, F., and Carulli, D. (2011). Experience-dependent plasticity and modulation of growth regulatory molecules at central synapses. PLoS ONE 6, e16666. doi:10.1371/journal.pone.0016666

Fox, K. (2002). Anatomical pathways and molecular mechanisms for plasticity in the barrel cortex. Neuroscience 111, 799-814.

Fox, K., and Wong, R. O. (2005). A comparison of experiencedependent plasticity in the visual and somatosensory systems. Neuron 48, 465-477.

Francis, D., Diorio, J., Plotky, P. M., and Meaney, M. J. (2002). Environmental enrichment reverses the effect of maternal separation on stress reactivity. J. Neurosci. 22, 7840-7843.

Frischknecht, R., Fejtova, A., Viesti, M., Stephan, A., and Sonderegger, P. (2008). Activity-induced synaptic capture and exocytosis of the neuronal serine protease neurotrypsin. J. Neurosci. 28, 1568-1579.

García-Alías, G., Barkhuysen, S., Buckle, M., and Fawcett, J. W. (2009). Chondroitinase $\mathrm{ABC}$ treatment opens a window of opportunity for taskspecific rehabilitation. Nat. Neurosci. 12, 1145-1151.

Garcia-Segura, L. M., RodriguezGonzalez, C., and Gonzalez-Ros, J. M. (1978). The effect of early experience on the exploratory behaviour, learning ability and on the synaptosomes of the mice brain. J. Hirnforsch. 19, 75-83.

Gaub, P., Joshi, Y., Wuttke, A., Naumann, U., Schnichels, S., Heiduschkam, P., and Di Giovanni, S. (2011). The histone acetyltransferase p300 promotes intrinsic axonal regeneration. Brain 134, 2134-2148.

Gaub, P., Tedeschi, A., Puttagunta, R. Nguyen, T., Schmandke, A., and Di Giovanni, S. (2010). HDAC inhibition promotes neuronal outgrowth and counteracts growth cone collapse through $\mathrm{CBP} / \mathrm{p} 300$ and P/CAF-dependent p53 acetylation. Cell Death Differ. 17, 1392-1408.

Gawlak, M., Gòrkiewicz, T., Gorlewicz, A., Konopacki, F. A., Kaczmarek, L., and Wilczynski, G. M. (2008). High resolution in situ zymography reveals matrix metalloproteinase activity at glutamatergic synapses. Neuroscience 158 , 167-176.

Ghiani, C. A., Ying, Z., de Vellis, J., and Gòmez-Pinilla, F. (2007). Exercise decreases myelin-associated glycoprotein expression in the spinal cord and positively modulates neuronal growth. Glia 55 966-975.

Girgis, J., Merrett, D., Kirkland, S., Metz, G. A. S., Verge, V., and Fouad, K. (2007). Reaching training in rats with spinal cord injury promotes plasticity and task specific recovery. Brain 130, 2993-3003.

Globus, A., Rosenzweig, M. R., Bennett, E. L., and Diamond, M. C. (1973). Effects of differential environments on dendritic spine counts. J. Comp. Physiol. Psychol. 84 598-604.

Gogolla, N., Caroni, P., Lüthi, A., and Herry, C. (2009). Perineuronal nets protect fear memories from erasure. Science 325, 1258-1261.

Goldshmit, Y., Lythgo, N., Galea, M. P., and Turnley, A. M. (2008).
Treadmill training after spinal cord hemisection in mice promotes axonal sprouting and synapse formation and improves motor recovery. J. Neurotrauma 25, 449-465.

Gòmez-Pinilla, F., Ying, Z., Agoncillo, T., and Frostig, R. (2011). The influence of naturalistic experience on plasticity markers in somatosensory cortex and hippocampus: effects of whisker use. Brain Res. 1388, 39-47.

Gòmez-Pinilla, F., Ying, Z., Roy, R. R., Molteni, R., and Edgerton, V. R. (2002). Voluntary exercise induces a BDNF-mediated mechanism that promotes neuroplasticity. J. Neurophysiol. 88, 2187-2195.

Gould, E., Beylin, A., Tanapat, P., Reeves, A., and Shors, T. J. (1999). Learning enhances adult neurogenesis in the hippocampal formation. Nat. Neurosci. 2, 260-265.

Greenough, W. T., Hwang, H. M., and Gorman, C. (1985). Evidence for active synapse formation or altered postsynaptic metabolism in visual cortex of rats reared in complex environments. Proc. Natl. Acad. Sci. U.S.A. 82, 4549-4552.

Gualandris, A., Jones, T. E., Strickland, S., and Tsirka, S. E. (1996). Membrane depolarization induces calcium-dependent secretion of tissue plasminogen activator. $\mathrm{J}$. $\mathrm{Neu}$ rosci. 16, 2220-2225.

Gupta, S., Kim, S. Y., Artis, S., Molfese, D. L., Schumacher, A., Sweatt, J. D., Paylor, R. E., and Lubin, F. D. (2010). Histone methylation regulates memory formation. J. Neurosci. 30, 3589-3599.

Harauzov, A., Spolidoro, M., DiCristo, G., De Pasquale, R., Cancedda, L., Pizzorusso, T., Viegi, A., Berardi, N., and Maffei, L. (2010). Reducing intracortical inhibition in the adult visual cortex promotes ocular dominance plasticity. J. Neurosci. 30, 361-371.

Heck, N., Garwood, J., Loeffler, J. P., Larmet, Y., and Faissner, A. (2004) Differential upregulation of extracellular matrix molecules associated with the appearance of granule cell dispersion and mossy fiber sprouting during epileptogenesis in a murine model of temporal lobe epilepsy. Neuroscience 129, 309-324.

Henderson, N. D. (1970). Brain weight increases resulting from environmental enrichment: a directional dominance in mice. Science 169, 776-778.

Henderson, N. D. (1973). Brain weight changes resulting from enriched rearing conditions: a diallel analysis. Dev. Psychobiol. 6, 367-376. 
Henderson, N. D. (1976). Short exposures to enriched environments can increase genetic variability of behavior in mice. Dev. Psychobiol. 9, 549-553.

Hensch, T. K. (2004). Criitcal period regulation. Annu. Rev. Neurosci. 27, 549-579.

Hickmott, P. W., and Steen, P. A. (2005). Large-scale changes in dendritic structure during reorganization of adult somatosensory cortex. Nat. Neurosci. 8, 140-142.

Hockfield, S., Kalb, R. G., Zaremba, S., and Fryer, H. (1990). Expression of neural proteoglycans correlates with the acquisition of mature neuronal properties in the mammalian brain. Cold Spring Harb. Symp. Quant. Biol. 55, 505-514.

Hofer, S. B., Mrsic-Flogel, T. D., Bonhoeffer, T., and Hübener, M. (2009). Experience leaves a lasting structural trace in cortical circuits. Nature 457, 313-317.

Holtmaat, A., Wilbrecht, L., Knott, G. W., Welker, E., and Svoboda, K. (2006). Experience-dependent and cell-type-specific spine growth in the neocortex. Nature 441, 979-983.

Holtmaat, A. J., Gorter, J. A., De Wit, J., Tolner, E. A., Spijker, S., Giger, R. J., Lopes da Silva, F. H., and Verhaagen, J. (2003). Transient downregulation of Sema3A mRNA in a rat model for temporal lobe epilepsy. A novel molecular event potentially contributing to mossy fiber sprouting. Exp. Neurol. 182, 142-150.

Horii-Hayashi, N., Yoshikawa, M., Matsusue, Y., Ishizaka, S., Nishi, M., and Wanaka, A. (2011). Environmental stimulation changes tissuetype plasminogen activator activity in the adult mouse hippocampus. Neurochem. Int. 58, 1-4.

Huck, U. W., and Price, E. O. (1975). Differential effects of environmental enrichment on the open-field behavior of wild and domestic Norway rats. J. Comp. Physiol. Psychol. 89, 892-898.

Hutchinson, K. J., Gòmez-Pinilla, F., Crowe, M. J., Ying, Z., and Basso, D. M. (2004). Three exercise paradigms differentially improve sensory recovery after spinal cord contusion in rats. Brain 127, 1403-1414.

Isaacs, K. R., Anderson, B. J., Alcantara, A. A., Black, J. E., and Greenough, W. T. (1992). Exercise and the brain: angiogenesis in the adult rat cerebellum after vigorous physical activity and motor skill learning. J. Cereb. Blood Flow Metab. 12, 110-119.

Jaenisch, R., and Bird, A. (2003). Epigenetic regulation of gene expression: how the genome integrates intrinsic and environmental signals. Nat. Genet. 33, 245-254.

Jones, T. A., and Schallert, T. (1994). Use-dependent growth of pyramidal neurons after neocortical damage. $J$. Neurosci. 14, 2140-2152.

Jørgensen, O. S., and Bock, E. (1979). Brain-specific proteins in the occipital cortex of rats housed in enriched and impoverished environments. Neurochem. Res. 4, 175-187.

Jourquin, J., Tremblay, E., Décanis, N., Charton, G., Hanessian, S., Chollet, A. M., Le Diguardher, T., Khrestchatisky, M., and Rivera, S. (2003). Neuronal activitydependent increase of net matrix metalloproteinase activity is associated with MMP-9 neurotoxicity after kainate. Eur. J. Neurosci. 18, 1507-1517.

Kalaska, J., and Pomeranz, B. (1979). Chronic paw denervation causes an age-dependent appearance of novel responses from forearm in "paw cortex" of kittens and adult cats. J. Neurophysiol. 42, 618-633.

Keck, T., Mrsic-Flogel, T. D., Vaz Afonso, M., Eysel, U. T., Bonhoeffer, T., and Hübener, M. (2008). Massive restructuring of neuronal circuits during functional reorganization of adult visual cortex. Nat. Neurosci. 11, 1162-1167.

Kelahan, A. M., and Doetsch, G. S. (1984). Time-dependent changes in the functional organization of somatosensory cerebral cortex following digit amputation in adult raccoons. Somatosens. Res. 2, 49-81.

Kempermann, G., Kuhn, H. G., and Gage, F. H. (1997). More hippocampal neurons in adult mice living in an enriched environment. Nature 386, 493-495.

Kempermann, G., Kuhn, H. G., and Gage, F. H. (1998). Experienceinduced neurogenesis in the senescent dentate gyrus. J. Neurosci. 18, 3206-3212.

Kim, B. G., Dai, H. N., McAtee, M., and Bregman, B. S. (2008). Modulation of dendritic spine remodeling in the motor cortex following spinal cord injury: effects of environmental enrichment and combinatorial treatment with transplants and neurotrophin-3. J. Comp. Neurol. 508, 473-486.

Kim, S. K., and Nabekura, J. (2011). Rapid synaptic remodeling in the adult somatosensory cortex following peripheral nerve injury and its association with neuropathic pain. $J$. Neurosci. 31, 5477-5482.

Kleim, J. A., Freeman, J. H. Jr., Bruneaur, R., Nolan, B. C., Cooper, N. R., Zook, A., and Walters, D. (2002). Synapse formation is associated with memory storage in the cerebellum. Proc. Natl. Acad. Sci. U.S.A. 99, 13228-13231.

Kleim, J. A., Jones, T. A., and Schallert, T. (2003). Motor enrichment and the induction of plasticity before or after brain injury. Neurochem. Res. 28, 1757-1769.

Kleim, J. A., Lussnig, E., Schwarz, E. R., Comery, T. A., and Greenough, W. T. (1996). Synaptogenesis and Fos expression in the motor cortex of the adult rat after motor skill learning. $J$. Neurosci. 16, 4529-4535.

Knott, G. W., Holtmaat, A., Wilbrecht, L., Welker, E., and Svoboda, K. (2006). Spine growth precedes synapse formation in the adult neocortex in vivo. Nat. Neurosci. 9, 1117-1124.

Knott, G. W., Quairiaux, C., Genoud, C., and Welker, E. (2002). Formation of dendritic spines with GABAergic synapses induced by whisker stimulation in adult mice. Neuron 34 265-273.

Kogan, J. H., Frankland, P. W., Blendy, J. A., Coblentz, J., Marowitz, Z., Schütz, G., and Silva, A. J. (1997). Spaced training induces normal long-term memory in CREB mutant mice. Curr. Biol. 7, 1-11.

Kolb, B., Cioe, J., and Comeau, W. (2008). Contrasting effects of motor and visual spatial learning tasks on dendritic arborization and spine density in rats. Neurobiol. Learn. Mem. 90, 295-300.

Konopacki, F. A., Rylski, M., Wilczek, E. Amborska, R., Detka, D., Kaczmarek, L., and Wilczynski, G. M. (2007). Synaptic localization of seizureinduced matrix metalloproteinase- 9 mRNA. Neuroscience 150, 31-39.

Korzus, E., Rosenfeld, M. G., and Mayford, M. (2004). CBP histone acetyltransferase activity is a critical component of memory consolidation. Neuron 42, 961-972.

Kossut, M., and Juliano, S. L. (1999). Anatomical correlates of representational map reorganization induced by partial vibrissectomy in the barrel cortex of adult mice. Neuroscience 92, 807-817.

Kozlowski, D. A., James, D. C., and Schallert, T. (1996). Use-dependent exaggeration of neuronal injury after unilateral sensorimotor cortex lesions. J. Neurosci. 16, 4776-4786.

Kuerzi, J., Brown, E. H., Shum-Siu, A., Siu, A., Burke, D., Morehouse, J., Smith, R. R., and Magnuson, D. S. (2010).Task-specificity vs. ceiling effect: step-training in shallow water after spinal cord injury. Exp. Neurol. 224, 178-187.

Kuzumaki, N., Ikegami, D., Tamura, R., Hareyama, N., Imai, S., Narita, M.
Torigoe, K., Niikura, K., Takeshima, H., Ando, T., Igarashi, K., Kanno, J., Ushijima, T., Suzuki, T., and Narita, M. (2011). Hippocampal epigenetic modification at the brain-derived neurotrophic factor gene induced by an enriched environment. Hippocampus 21, 127-132.

Kwok, J. C., Afshari, F., García-Alías, G., and Fawcett, J. W. (2008). Proteoglycans in the central nervous system: plasticity, regeneration and their stimulation with chondroitinase ABC. Restor. Neurol. Neurosci. 26, 131-145.

Lattal, K. M., Barrett, R. M., and Wood, M. A. (2007). Systemic or intrahippocampal delivery of histone deacetylase inhibitors facilitates fear extinction. Behav. Neurosci. 121, 1125-1131.

Leslie, J. H., and Nedivi, E. (2011). Activity-regulated genes as mediators of neural circuit plasticity. Prog. Neurobiol. 94, 223-237.

Levenson, J. M., O’Riordan, K. J., Brown, K. D., Trinh, M. A., Molfese, D. L., and Sweatt, J. D. (2004). Regulation of histone acetylation during memory formation in the hippocampus. J. Biol. Chem. 279, 40545-40559.

Levenson, J. M., Roth, T. L., Lubin, F. D., Miller, C. A., Huang, I. C., Desai, P., Malone, L. M., and Sweatt, J. D. (2006). Evidence that DNA (cytosine-5) methyltransferase regulates synaptic plasticity in the hippocampus. J. Biol. Chem. 281, 15763-15773.

Levitan, I. B., Mushynski, W. E., and Ramirez, G. (1972). Effects of an enriched environment on amino acid incorporation into rat brain sub-cellular fractions in vivo. Brain Res. 41, 498-502.

Lin, Y., Bloodgood, B. L., Hauser, J. L., Lapan, A. D., Koon, A. C., Kim, T. K., Hu, L. S., Malik, A. N., and Greenberg, M. E. (2008). Activitydependent regulation of inhibitory synapse development by Npas4. Nature 455, 1198-1204.

Lyons, M. R., and West, A. E. (2011). Mechanisms of specificity in neuronal activity-regulated gene transcription. Prog. Neurobiol. 94, 259-295.

Maffei, L. (2002). Plasticity in the visual system: role of neurotrophins and electrical activity. Arch. Ital. Biol. 140, 341-346.

Maier, I. C., Baumann, K., Thallmair, M., Weinmann, O., Scholl, J., and Schwab, M. E. (2008). Constraintinduced movement therapy in the adult rat after unilateral corticospinal tract injury. J. Neurosci. 28, 9386-9403. 
Mansuy, I. M., Mayford, M., Jacob, B., Kandel,E. R., and Bach, M.E. (1998). Restricted and regulated overexpression reveals calcineurin as a key component in the transition from shortterm to long-term memory. Cell 92, 39-49.

Martin, S. J., Grimwood, P. D., and Morris, R. G. (2000). Synaptic plasticity and memory: an evaluation of the hypothesis. Annu. Rev. Neurosci. 23, 649-711.

Mataga, N., Mizuguchi, Y., and Hensch, T. H. (2004). Experience-dependent pruning of dendritic spines in visual cortex by tissue plasminogen activator. Neuron 44, 1031-1041.

Mataga, N., Nagai, N., and Hensch, T. H. (2002). Permissive proteolytic activity for visual cortical plasticity. Proc. Natl. Acad. Sci. U.S.A. 99, 7717-7721.

Meffert, M. K., Chang, J. M., Wiltgen, B. J., Fanselow, M. S., and Baltimore, D. (2003). NF-kappa B functions in synaptic signaling and behavior. Nat. Neurosci. 6, 1071-1078.

Merzenich, M. M., Kaas, J. H., Wall, J. T., Sur, M., Nelson, R. J., and Fellman, D. J. (1983a). Progression of change following median nerve section in the cortical representation of the hand in areas $3 \mathrm{~b}$ and 1 in adult owl and squirrel monkeys. Neuroscience 10, 639-665.

Merzenich, M. M., Kaas, J. H., Wall, J., Nelson, R. J., Sur, M., and Fellman, D. (1983b). Topographic reorganization of somatosensory cortical areas $3 \mathrm{~b}$ and 1 in adult monkeys following restricted deafferentation. Neuroscience 8, 33-55.

Merzenich, M. M., Nelson, R. J., Stryker, M. P., Cynader, M. S., Schoppmann, A., and Zook, J. M. (1984). Somatosensory cortical map changes following digit amputation in adult monkeys. J. Comp. Neurol. 224, 591-605.

Michaluk, P., Kolodziej, L., Mioduszewska, B., Wilczynski, G. M., Dzwonek, J., Jaworski, J., orecki, D. C., Otersen, O. P., and Kaczmarek, L. (2007). Beta-dystroglycan as a target for MMP-9, in response to enhanced neuronal activity. J. Biol. Chem. 282, 16036-16041.

Michaluk, P., Mikasova, L., Groc, L., Frischknecht, R., Choquet, D., and Kaczmarek, L. (2009). Matrix metalloproteinase-9 controls NMDA receptor surface diffusion through integrin betal signaling. $J$. Neurosci. 29, 6007-6012.

Miller, C. A., Campbell, S. L., and Sweatt, J. D. (2008). DNA methylation and histone acetylation work in concert to regulate memory formation and synaptic plasticity. Neurobiol. Learn. Mem. 89, 599-603.

Miyata, S., Akagi, A., Hayashi, N., Watanabe, K., and Oohira, A. (2004). Activity-dependent regulation of a chondroitin sulfate proteoglycan 6B4 phosphacan/RPTPbeta in the hypothalamic supraoptic nucleus. Brain Res. 1017, 163-171.

Mohammed, A. H., Henriksson, B. G., Söderström, S., Ebendal, T., Olsson, T., and Seckl, J. R. (1993). Environmental influences on the central nervous system and their implications for the aging rat. Behav. Brain Res. 57, 183-191.

Molteni, R., Zheng, J. Q., Ying, Z., Gòmez-Pinilla, F., and Twiss, J. L. (2004). Voluntary exercise increases axonal regeneration from sensory neurons. Proc. Natl. Acad. Sci. U.S.A. 101, 8473-8478.

Morita, S., Oohira, A., and Miyata, S. (2010). Activity-dependent remodeling of chondroitin sulfate proteoglycans extracellular matrix in the hypothalamoneurohypophysial system. Neuroscience 166, 1068-1082.

Morley-Fletcher, S., Rea, M., Maccari, S., and Laviola, G. (2003). Environmental enrichment during adolescence reverses the effects of prenatal stress on play behaviour and HPA axis reactivity in rats. Eur. J. Neurosci. 18, 3367-3374.

Moser, M. B. (1999). Making more synapses: a way to store information? Cell. Mol. Life Sci. 55, 593-600.

Moser, M. B., Trommald, M., and Andersen, P. (1994). An increase in dendritic spine density on hippocampal CA1 pyramidal cells following spatial learning in adult rats suggests the formation of new synapses. Proc. Natl. Acad. Sci. U.S.A. 91, 12673-12675.

Mower, A. F., Liao, D. S., Nestler, E. J., Neve, R. L., and Ramoa, A. S. (2002). cAMP/Ca2+ response element-binding protein function is essential for ocular dominance plasticity. J. Neurosci. 22, 2237-2245.

Mushynski, W. E., Levitan, I. B., and Ramirez, G. (1973). Competition hybridization studies on brain ribonucleic acid from rats reared in enriched and deprived environments. J. Neurochem. 20, 309-317.

Navarro, X., Vivò, M., and Valero-Cabré, A. (2007). Neural plasticity after peripheral nerve injury and regeneration. Prog. Neurobiol. 82, 163-201.

Neves, G., Cooke, S. F., and Bliss, T. V. (2008). Synaptic plasticity, memory and the hippocampus: a neural network approach to causality. Nat. Rev. Neurosci. 9, 65-75.
Nithianantharajah, J., and Hannan, A. J. (2006). Enriched environments, experience-dependent plasticity and disorders of the nervous system. Nat. Rev. Neurosci. 7, 697-709.

Nudo, R. J., Wise, B. M., SiFuentes, F., and Milliken, G. W. (1996a). Neural substrates for the effects of rehabilitative training on motor recovery after ischemic infarct. Science 272 , 1791-1794.

Nudo, R. J., Milliken, G. W., Jenkins, W. M., and Merzenich, M. M. (1996b). Use-dependent alterations of movement representations in primary motor cortex of adult squirrel monkeys. J. Neurosci. 16, 785-807.

Oliveira, A. M., Wood, M. A., McDonough, C. B., and Abel, T. (2007). Transgenic mice expressing an inhibitory truncated form of p300 exhibit long-term memory deficits. Learn. Mem. 14, 564-572.

Oray, S., Majewska, A., and Sur, M. (2004). Dendritic spine dynamics are regulated by monocular deprivation end extracellular matrix degradation. Neuron 44, 1021-1030.

Pascual-Leone, A., and Torres, F. (1993). Plasticity of the sensorimotor cortex representation of the reading finger in Braille readers. Brain 116, 39-52.

Peterson, C. L., and Laniel, M. A. (2004). Histones and histone modifications. Curr. Biol. 14, 546-551.

Pizzorusso, T., Medini, P., Berardi, N. Chierzi, S., Fawcett, J. W., and Maffei, L. (2002). Reactivation of ocular dominance plasticity in the adult visual cortex. Science 298, 1248-1251.

Pons, T. P., Garraghty, P. E., Ommaya, A. K., Kaas, J. H., Taub, E., and Mishkin, M. (1991). Massive cortical reorganization after sensory deafferentation in adult macaques. Science 252 , 1857-1860.

Putignano, E., Lonetti, G., Cancedda, L. Ratto, G., Costa, M., Maffei, L., and Pizzorusso, T. (2007). Developmental downregulation of histone posttranslational modifications regulates visual cortical plasticity. Neuron 53, 747-759.

Rajan, R., Irvine, D. R., Wise, L. H., and Heil, P. (1993). Effect of unilateral partial cochlear lesions in adult cats on the representation of lesioned and unlesioned cochleas in primary auditory cortex. J. Comp. Neurol. 338, 17-49.

Ramachandran, V. S. (1993). Behavioral and magnetoencephalographic correlates of plasticity in the adult human brain. Proc. Natl. Acad. Sci. U.S.A. 90, 10413-10420.

Rampon, C., Jiang, C. H., Dong, H., Tang, Y. P., Lockhart, D. J., Schultz,
P. G., Tsien, J. Z., and Hu, Y. (2000). Effects of environmental enrichment on gene expression in the brain. Proc. Natl. Acad. Sci. U.S.A.97, 12880-12884.

Rasmusson, D. D. (1982). Reorganization of raccoon somatosensory cortex following removal of the fifth digit. J. Comp. Neurol. 205, 313-326.

Recanzone, G. H., Merzenich, M. M., and Jenkins, W. M. (1992a) Frequency discrimination training engaging a restricted skin surface results in an emergence of a cutaneous response zone in cortical area 3a. J. Neurophysiol. 67, 1057-1070.

Recanzone, G. H., Marzenich, M. M., Jenkins, W. M., Grajski, K. A., and Dinse, H. R. (1992b). Topographic reorganization of the hand representation in cortical area $3 \mathrm{~b}$ owl monkeys trained in a frequencydiscrimination task. J. Neurophysiol. 67, 1031-1056.

Reichardt, L. F. (2006). Neurotrophinregulated signalling pathways. Philos. Trans. R. Soc. Lond. B Biol. Sci. 361, 1545-1564.

Risedal, A., Zeng, J., and Johansson, B. B. (1999). Early training may exacerbate brain damage after focal brain ischemia in the rat. J. Cereb. Blood Flow Metab. 19, 997-1003.

Robertson, D., and Irvine, D. R. (1989). Plasticity of frequency organization in auditory cortex of guinea pigs with partial unilateral deafness. $J$. Comp. Neurol. 282, 456-471.

Rosenzweig, M. R., Bennett, E. L., Hebert, M., and Morimoto, H. (1978). Social grouping cannot account for cerebral effects of enriched environments. Brain Res. 153, 563-576.

Rossi, F., Gianola, S., and Corvetti, L. (2007). Regulation of intrinsic neuronal properties for axon growth and regeneration. Prog. Neurobiol. 81, 1-28.

Sale, A., Berardi, N., and Maffei, L. (2009). Enrich the environment to empower the brain. Trends Neurosci. 32, 233-239.

Sale, A., Maya Vetencourt, J. F., Medini, P., Cenni, M. C., Baroncelli, L., De Pasquale, R., and Maffei, L. (2007). Environmental enrichment in adulthood promotes amblyopia recovery through a reduction of intracortical inhibition. Nat. Neurosci. 10, 679-681.

Schwaber, M. K., Garraghty, P. E., and Kaas, J. H. (1993). Neuroplasticity of the adult primate auditory cortex following cochlear hearing loss. Am. J. Otol. 14, 252-258. 
Schwarzacher, S. W., Vuksic, M., Haas, C. A., Burbach, G. J., Sloviter, R. S., and Deller, T. (2006). Neuronal hyperactivity induces astrocytic expression of neurocan in the adult rat hippocampus. Glia 53, 704-714.

Sheng, M., and Greenberg, M. E. (1990). The regulation and function of $\mathrm{c}$ fos and other immediate early genes in the nervous system. Neuron 4, 477-485.

Shin, C. Y., Kundel, M., and Wells, D. G. (2004). Rapid, activityinduced increase in tissue plasminogen activator is mediated by metabotropic glutamate receptordependent mRNA translation. $J$. Neurosci. 24, 9425-9433.

Soffie, M., Hahn, K., Terao, E., and Eclancher, F. (1999). Behavioural and glial changes in old rats following environmental enrichment. Behav. Brain Res. 101, 37-49.

Starkey, M. L., Barritt, A. W., Yip, P. K., Davies, M., Hamers, F. P., McMahon, S. B., and Bradbury, E. J. (2005). Assessing behavioural function following a pyramidotomy lesion of the corticospinal tract in adult mice. Exp. Neurol. 195, 524-539.

Swain, R. A., Harris, A. B., Wiener, E. C., Dutka, M. V., Morris, H. D., Theien, B. E., Konda, S., Engberg, K., Lauterbur, P. C., and Greenough, W. T. (2003). Prolonged exercise induces angiogenesis and increases cerebral blood volume in primary motor cortex of the rat. Neuroscience 117, 1037-1046.

Sweatt, J. D. (2009). Experiencedependent epigenetic modifications in the central nervous system. Biol. Psychiatry 65, 191-197.

Szeligo, F., and Leblond, C. P. (1977). Response of three main types of glial cells of cortex and corpus callosum in rats handled during suckling or exposed to enriched, control, or impoverished envrionments following weaning. J. Comp. Neurol. 172, 247-264.

Szklarczyk, A., Lapinska, J., Rylski, M., McKay, R. D., and Kaczmarek, L. (2002). Matrix metalloproteinase- 9 undergoes expression and activation during dendritic remodeling in adult hippocampus. J. Neurosci. 22, 920-930.

Trachtenberg, J. T., Chen, B. E., Knott, G. W., Feng, G., Sanes, J. R., Welker, E., and Svoboda, K. (2002). Longterm in vivo imaging of experiencedependent synaptic plasticity in adult cortex. Nature 420, 788-794.

Uphouse, L. L., and Bonner, J. (1975). Preliminary evidence for the effects of environmental complexity on hybridization of rat brain RNA to rat unique DNA. Dev. Psychobiol. 8, 171-178.

Vallès, A., Boender, A. J., Gijsbers, S., Haast, R. A., Martens, G. J., and de Weerd, P. (2011). Genomewide analysis of rat barrel cortex reveals time- and layerspecific mRNA expression changes related to experience-dependent plasticity. J. Neurosci. 31, 6140-6158.

Van Praag, H., Kempermann, G., and Gage, F. H. (1999). Running increases cell proliferation and neurogenesis in the adult mouse dentate gyrus. Nat. Neurosci. 2, 266-270.

Van Praag, H., Kempermann, G., and Gage, F. H. (2000). Neural consequences of environmental enrichment. Nat. Rev. Neurosci. 1, 191-198.

Vaynman, S., and Gomez-Pinilla, F. (2005). License to run: exercise impacts functional plasticity in the intact and injured central nervous system by using neurotrophins. Neruorehabil. Neural Repair 19, 283-295.

Vecsey, C. G., Hawk, J. D., Lattal, K. M., Stein, J. M., Fabian, S. A., Cabrera, S. M., McDonough, C. B., Brindle, P. K., Abel, T., and Wood, M. A. (2007). Histone deacetylase inhibitors enhance memory and synaptic plasticity via CREB:CBP-dependent transcriptional activation. J. Neurosci. 27, 6128-6140.

Wall, J. T., and Cusick, C. G. (1984). Cutaneous responsiveness in primary somatosensory (S-I) hindpaw cortex before and after partial hindpaw deafferentation in adult rats. J. Neurosci. 4, 1499-1515.

Weidner, N., Ner, A., Saimi, N., and Tuszynski, M. H. (2001). Spontaneous corticospinal axonal plasticity and functional recovery after adult central nervous system injury. Proc. Natl. Acad. Sci. U.S.A. 98 3513-3518.

Wellmann, H., Kaltschmidt, B., and Kaltschmidt, C. (2001). Retrograde transport of transcription factor NFkappa B in living neurons. J. Biol. Chem. 276, 1821-11829.

Whishaw, I. Q., Gorny, B., and Sarna, J. (1998). Paw and limb use in skilled and spontaneous reaching after pyramidal tract, red nucleus and combined lesions in the rat behavioral and anatomical dissociations. Behav. Brain Res. 93, 167-183.

Wibrand, K., Messaoudi, E., Håvik, B. Steenslid, V., Løvlie, R., Steen, V. M. and Bramham, C. R. (2006). Identification of genes co-upregulate with Arc during BDNF-induced longterm potentiation in adult rat dentate gyrus in vivo. Eur. J. Neurosci. 23, 1501-1511.

Wilczynski, G. M., Konopacki, F. A., Wilczek, E., Lasiecka, Z., Gorlewicz, A., Michaluk, P., Wawrzynian, M., Malinowska, M., Okulski, P., Kolodziej, L. R., Konopka, W., Duniec, K., Mioduszewska, B. Nikolaev, E., Walczak, A., Owczarek, D., Gorecki, D. C., Zuschratter, W., Ottersen, O. P., and Kaczmarek, L. (2008). Important role of matrix metalloproteinase 9 in epileptogenesy. J. Cell Biol. 180, 1021-1035.

Winocur, G. (1998). Environmental influences on cognitive decline in aged rats. Neurobiol. Aging 19, 589-597.

Wu, Y. P., Siao, C. J., Lu, W., Sung, T. C., Frohman, M. A., Milev, P., Degen, J. L., Levine, J. M., Margolis, R. U., and Tsirka, S. E. (2000). The tissue plasminogen activator (tPA)/plasmin extracellular proteolytic system regulates seizure-induced hippocampal mossy fiber outgrowth through a proteoglycan substrate. J. Cell Biol. 148, 1295-1304.

Xie, F., and Zheng, B. (2008). White matter inhibitors in CNS axon regeneration failure. Exp. Neurol. 209, 302-312.

Xu, T., Yu, X., Perlik, A. J., Tobin, W. F., Zweig, J. A., Tennant, K., Jones, T., and Zuoi, Y. (2009). Rapid formation and selective stabilization of synapses for enduring motor memories. Nature 462, 915-919.

Yang, G., Pan, F., and Gan, W. B. (2009). Stably maintained dendritic spines are associated with lifelong memories. Nature 462, 920-924.

Yeh, S. H., Lin, C. H., and Gean, P. W. (2004). Acetylation of nuclear factor-kappaB in rat amygdala improves long-term but not shortterm retention of fear memory. Mol Pharmacol. 65, 1286-1292.

Ying, Z., Roy, R. R., Zhong, H., Zdunowski, S., Edgerton, V. R., and Gomez-Pinilla, F. (2008). BDNFexercise interaction in the recovery of symmetrical stepping after a cervical hemisection in rats. Neuroscience $155,1070-1078$.

Conflict of Interest Statement: The authors declare that the research was conducted in the absence of any commercial or financial relationships that could be construed as a potential conflict of interest.

Received: 26 August 2011; paper pending published: 13 October 2011; accepted: 11 November 2011; published online: 28 November 2011.

Citation: Carulli D, Foscarin S and Rossi F (2011) Activity-dependent plasticity and gene expression modifications in the adult CNS. Front. Mol. Neurosci. 4:50. doi: 10.3389/fnmol.2011.00050

Copyright $\odot 2011$ Carulli, Foscarin and Rossi. This is an open-access article distributed under the terms of the Creative Commons Attribution Non Commercial License, which permits use, distribution, and reproduction in other forums, provided the original authors and source are credited. 